\title{
Splenic vessel bleeding in puerperium: a rare maternal near miss case
}

\author{
Meetali Parashar ${ }^{1 *}$, Meena Mehta ${ }^{2}$
}

\begin{abstract}
${ }^{1}$ Department of Obstetrics and Gynecology, Dumka Medical College and Hospital, Dumka, Jharkhand, India
${ }^{2}$ Department of Obstetrics and Gynecology, RIMS, Ranchi, Jharkhand, India
\end{abstract}

Received: 18 October 2019

Revised: 02 January 2020

Accepted: 06 January 2020

\author{
*Correspondence: \\ Dr. Meetali Parashar, \\ E-mail: mparashar04@gmail.com
}

Copyright: () the author(s), publisher and licensee Medip Academy. This is an open-access article distributed under the terms of the Creative Commons Attribution Non-Commercial License, which permits unrestricted non-commercial use, distribution, and reproduction in any medium, provided the original work is properly cited.

\begin{abstract}
Splenic rupture is a very rare entity during pregnancy and puerperium. It has a very high maternal mortality if not diagnosed and managed in time. Here we are presenting a very rare case of splenic haemorrhage on day 5 lower segment caeserian section which was diagnosed and managed at RIMS, Ranchi, Jharkhand, India.
\end{abstract}

Keywords: Hemoperitoneum, Laparotomy, Maternal near miss case, Preeclampsia, Splenic hemorrhage, Splenic rupture

\section{INTRODUCTION}

Splenic rupture is a very rare entity during pregnancy and puerperium. It has a very high maternal mortality if not diagnosed and managed in time. Here we are presenting a very rare case of splenic haemorrhage on day 5 lower segment caeserian section which was diagnosed and managed at RIMS, Ranchi, Jharkhand, India. This case is being reported because very few cases of splenic injury in pregnancy or puerperium have been reported from India and this case will add to the number. Moreover, this case emphasizes the need to keep the differential diagnosis of splenic hemorrhage in cases of hemoperitoneum found in pregnancy or puerperium.

\section{CASE REPORT}

A 23-year primigravida booked case was admitted in labour room, RIMS, Ranchi, Jharkhand with mildpre eclampsia in early labour with breech presentation. She had mild pallor, mild icterus and mild edema. Her BP was $140 / 90 \mathrm{mmHg}$, pulse rate was $84 / \mathrm{min}$ and urine dipstick was 1+. LSCS was done delivering an alive term baby. There was no intraoperative complication. After 18 hours observation in labour room, patient was shifted to the maternity ward. Gradually, her pallor and icterus increased on $5^{\text {th }}$ postoperative day and was shifted to obstetric ICU. Her investigations showed Hb-3.7 gm\%, total bilirubin $-4.8 \mathrm{mg} / \mathrm{dl}$, direct bilirubin $-4.0 \mathrm{mg} / \mathrm{dl}$, LDH -1028 IU/L, PT -12.5 sec, BT and CT was normal. 2 units whole blood transfusion was given. On $6^{\text {th }}$ postoperative day, she started developing abdominal distension and her pallor increased. Ultrasonography was done and there was gross hemoperitoneum. Immediately, laparotomy was done there was hemoperitoneum of about 2.5 litres. Profuse fresh bleeding was coming but no source of bleeding could be found in and around the uterus. So, abdominal incision was extended up to the xiphisternum and entire abdominal cavity was explored to find the source of bleeding.

We found that profuse bleeding was coming from splenic hilum. Hemostasis was secured and intraperitoneal drain given. Postoperatively, she was given 6 more units of packed cell, and 6 units of FFP and 6 units of platelets. She was investigated for the cause of splenic bleeding but exact cause could not be identified. Her post-laparotomy 
period was uneventful. She recovered very well and both mother and baby were discharged on $10^{\text {th }}$ postlaparotomy day.

\section{DISCUSSION}

The spleen is the most common intra- abdominal organ injured in blunt trauma. Splenic injuries vary from simple tranverse tear of the parenchyma to transverse crack of the hilus. There may be subcapsular hematoma only in minor cases or there may be complete disruption of the organ and its vessels in the fulminating injuries. There are 3 main types of rupture in spleen-

\section{Acute rupture}

Which occurs mostly due to blunt trauma and is featured by immediate intraperitoneal bleeding

\section{Delayed rupture}

In this type after an interval of a few days to weeks after injury, sudden intraperitoneal bleeding starts. Such delayed type of rupture is probably due to (a) blood clot, temporarily sealing the rent, becomes lysed by the enzymes of the lacerated tail of the pancreas (b) slowly enlarging subcapsular haematoma which eventually ruptures or (c) the greater omentum shuts off the injured site initially, gradually moves off.

\section{Occult rupture}

It is caused by organization of intrasplenic or parasplenic hematoma. ${ }^{1}$

The etiology of splenic rupture is traditionally divided into traumatic or spontaneous rupture. The latter is usually associated with a prior splenic disease, which is then termed pathological rupture. Splenic rupture can occur with any degree of trauma to a normal spleen or minimal trauma to a diseased spleen. However, spontaneous rupture in pregnancy without antecedent trauma is rare and occurs most commonly in the third trimester or puerperium. ${ }^{2}$ To be labeled as spontaneous, the splenic rupture should not be associated with a history of antecedent trauma, any systemic disease, or evidence of gross pathology at the time of exploration , and the spleen parenchyma, vasculature, and capsule should be normal macroscopically and histologically. Since the first case of splenic rupture in pregnancy was reported by Saxtroph in 1803, many case reports and series have been published, which suggests that this entity is not as rare as was once thought. Furthermore, the lethality and the devastating consequences for both mother and fetus from failure of preoperative diagnosis give this entity great importance. ${ }^{3}$

The theory of spontaneous postpartum splenic rupture remains unknown. It has been suggested that splenic enlargement and increased blood volume normally seen in pregnancy in addition to the trauma of parturition could be implicated in the pathogenesis of some cases of splenic rupture, but this is controversial. Traction with undue force with sharp- or blunt-edged instruments during cesarean delivery and insertion of packs could theoretically cause abrasive injuries to an already congested organ such as the spleen. Excessive force in exploring the upper abdomen and manual expression of the fetus by forceful pushing on the upper abdomen at the time of cesarean delivery or even while removing clots from the paracolic gutters might lead to splenic injury. ${ }^{4}$ Several authors have suggested as short splenic pedicle or deeply recessed location of the spleen as congenital factors that might contribute to rupture by compressing the diaphragm during coughing, sneezing, or vomiting. ${ }^{5}$ In our case, delayed splenic rupture/ injury may be due to fundal pressure applied to deliver the head after the delivery of shoulder.

Patients with splenic rupture usually present with severe abdominal pain that can be localized to the left upper quadrant in the early stages and associated with chest and shoulder pain. This pain can then become generalized, with distention and rigidity in later stages. Eventually more than half of the patients will suffer hemorrhagic shock if the condition is left untreated. ${ }^{6}$ In this case, patient had neither complain of abdominal pain, chest pain or shoulder pain. She had slow developing abdominal distension, increasing pallor and tachycardia and restlessness. It was the bedside ultrasound that helped us in diagnosing the case and immediate laparotomy was done.

The other causes of spontaneous splenic rupture in the general, nonpregnant population includes local splenic disorders, such as splenic cysts and diffuse angiomatosis; hematologic diseases, such as hemophilia, congenital afibrinogenemia, and hemolytic anemia; metabolic disorders, such as amyloidosis, Wilson's disease, Gaucher's and Niemann-Pick disease; drug-induced, such as intravenous heparin, warfarin, and streptokinase; iatrogenic causes, such as extracorporeal shock wave lithotripsy and clamping of the portal triad; and miscellaneous, such as vomiting, uremia, systemic lupus erythematosus and other connective tissue disease. Most notable in the differential diagnosis are the infectious causes, such as infectious mononucleosis, which is considered the most common cause of spontaneous splenic rupture, as well as malaria. ${ }^{7}$ Cases of splenic rupture with pre-eclampsia, autoimmunity and antiphopholipid antibody syndrome have been reported in literature. ${ }^{8}$ Although the association between preeclampsia and hepatic subcapsular or ruptured hematoma is well understood, the association with splenic rupture is rare. Similarly, our case had pre-eclampsia which could be the cause of spontaneous splenic hemorrhage.

Exact cause of splenic hemorrhage in this case could not be found, but a provisional diagnosis of pre-eclampsia 
with blunt abdominal injury inflicted during caeserian section was made.

\section{CONCLUSION}

Splenic hemorrhage should be kept in mind in case of hemoperitoneum found in LSCS patients. A careful postoperative examination aided by supportive investigations, a suspicious clinical mind and a quick decision of laparotomy can save many maternal deaths.

\section{ACKNOWLEDGMENTS}

Authors would like to thank Dr Anupama, Dr Qadir, Dr Chandna, Dr Bela, Dr Ranjana and Dr Veenu who encouraged to complete the paper. The author would also like to thank the patient who gave permission for publication of this case.

Funding: No funding sources

Conflict of interest: None declared

Ethical approval: Not required

\section{REFERENCES}

1. Das S. A Concise Textbook of Surgery. $5^{\text {th }}$ Edition. Calcutta Dr. S Das; 2008.
2. Mc Cormick GM, Young DB. Spontaneous rupture of the spleen. A fatal complication of pregnancy. Am J Forensic Med Pathol. 1995;16:132-4.

3. Sparkman RS. Rupture of the spleen in pregnancy: report of two cases and review of the literature. Am J Obstet Gynecol. 1958;76:587-98.

4. Sakhel K, Aswad N, Usta I, Nassar A. Postpartum splenic rupture. Obstet Gynecol. 2003;102:1207-10.

5. Orloff M, Peskin G. Spontaneous rupture of the normal spleen: a surgical enigma. Int Abs Surg. 1958;106:1-5.

6. Denehy T, McGrath EW, Breen JL. Splenic torsion and rupture in pregnancy. Obstet Gynecol Surv. 1988;43:123-31.

7. Debnath D, Valerio D. A traumatic rupture of the spleen. J R Coll Surg Edinb. 2002;47:437-45.

8. Adler Lazarovits $\mathrm{C}$, Mazor M, Erez O. Autoimmunity, preeclampsia and splenic rupture: a case report and literature review. Case Rep Perinat Med. 2014;3(1):27-30.

Cite this article as: Parashar M, Mehta M. Splenic vessel bleeding in puerperium: a rare maternal near miss case. Int J Reprod Contracept Obstet Gynecol 2020;9:871-3. 